\title{
MANAGERIAL NEURO - HETERODOX ATTITUDE IN DISORDERED SCENARIO
}

\author{
${ }^{1}$ Col Prof Dr. J Satpathy, ${ }^{2}$ Prof Dr. Kalpana Sahoo, ${ }^{3}$ Vedanshi Jalan, \\ ${ }^{4}$ Lidija Weiss, ${ }^{5}$ Chethana, M, ${ }^{6}$ Prof Keerthan Raj, ${ }^{7}$ Prof Adyasha Das, \\ ${ }^{8}$ Prof Anita Singh, ${ }^{9}$ Prof Washington Okeyo, ${ }^{10}$ Dr Sonia Lohana , \\ ${ }^{11}$ Prof Monica Apte, ${ }^{12}$ Sebastian Laza, ${ }^{13}$ Ana Maria Da Palma Moreira \\ ${ }^{1}$ Professor, Srinivas University, India \& Visiting Professor, Management University of \\ Africa, Nairobi, Kenya \\ ${ }^{2}$ Faculty, XIM University, Bhubaneswar and PDF Researcher, Srinivas University, India \\ ${ }^{3}$ Graduate Scholar, School of Law, XIM University, India \\ ${ }^{4}$ Dean, Ljubljana School of Business, Lubjana, Slovenia \\ ${ }^{5}$ Chethana, M., Ph. D Researcher, Srinivas University, India \\ ${ }^{6}$ Dean, Dept of Management, Srinivas University, India \\ ${ }^{7}$ Faculty, Dept of Management, IITTM, India \\ ${ }^{8}$ Professor School of Law, Sharada University, India \\ ${ }^{9}$ Vice - Chancellor, Management University of Africa, Nairobi, Kenya \\ ${ }^{10}$ Researcher, Management, Universiti Tun Hussein Onn Malaysia (UTHM), Malaysia \\ ${ }^{11}$ Faculty, Dept of MCA, Suryadutta Group of Institutions, India \\ ${ }^{12}$ Sebastian Laza, Executive Director, School of Applied Neurosciences, National \\ University of Cuoyo, Argentina \\ ${ }^{13}$ Institute of Psychological, Social and Life Sciences (ISPA), Lisbon, Portugal
}

"Talent management is the "attraction, development, and retention" of the talents, i.e., the most valuable staff members, by creating conditions conducive to their potential development, so that they can be put to use for the company's operations for as long as possible." - B. Jamka

\begin{abstract}
As a generation that lived through a disorder like DISORDER 19, mankind has been exposed to tremendous challenges and changes of high magnitude. While some changes were favourable and some adverse, mankind was forced to accept and adapt to them. When survival became sole priority, businesses around the world had to step up and respond to adversities selflessly. The disorder brought in a lot of drastic changes in business landscape all around the world. Along with changes in methodologies and functioning of firms, change in creative neuro - heterodox - attitude of business leaders has become need of hour. An impresario is, "A person who manages, organises, and bears risks of a company or corporation." For such people, disorder is a major disruption which put forth humungous challenges as well as possibilities. But to tackle this and do justice to responsibility amidst disorder requires person to be headstrong. Also, impacts of disorder on economy have been
\end{abstract}


described as "The deepest recession since Second World War". While DISORDER'19 has a wide-ranging influence on society, including changes in consumption habits, increased anxiety and depression risks, lower psychological sustainability and quality of life, economic impact on enterprises has been unparalleled. Though lockdown measures were extremely effective in controlling spread of disease, it brought in other adverse effects. The lockdown highlighted critical and sensitive issues like gender inequalities, and thus reducing psychological sustainability. Managership, has potential for creating huge positive impact socially and in the sustainable development of the economy. However, studies reveal that managership too has been through changes with visible drop in managership during lockdown. That aside, disorder also made impresarios incorporate vital and changes in CSR projects. Also, we saw the rise of opportunity motivated managership after lockdown measures gradually started to fade.

Purpose: In this paper, we start out by discussing impact of disorder on various aspects of business landscape and then move on to understand behavioural changes due to disorder. Following that we compare and contrast effects of DISORDER-19 on managership. Creative neuro - heterodox attitude before and after lockdown and then understand social managership in disorder era. The extremely dynamic and turbulent business environment makes it crucial for organizations to be flexible and agile.

Objective: The objective of this paper is to bring out a clear perception about talent management and its recent trends, right beginning from definition of talent-to-talent managements and its trends.

Findings/Result: Organizations need to adapt and equip themselves with changes taking place to sustain and flourish in hostile environment. To be in top scorers, quality of human resources is critical area of consideration for top management. This complex business environment has led to need for exceptional and talented market penetrators who are equipped with all the skills so as to lead organization towards achievement of vision, mission and objectives. The acquisition retention of talented personnel has become strategic objective of human resource management. HR these days is hugely loaded and is quite particular about employment and training of personnel's so as to exploit the maximum potential of an individual. It has become critical for HR to deploy right number of people in right departments so as to generate maximum output and lead organization towards right path. Human resources are considered to be the most important asset of organization. So, it is essential that right assets are chosen and for it the talent recognition and management is very important.

Originality and value: A comprehensive conceptual analysis and interpretation has been made to cover the concerned topic of study and make information more reliable and valid. A new initiative is taken to provide information pertaining to managerial neuro - heterodox attitude in disordered scenario

Paper Type: Conceptual analysis / interpretive paper

Key Words: Managerial Decision, Neuro - Heterodox Attitude and Disordered Scenario 


\section{Introduction}

DISORDER 19 ushered in a slew of disruptive developments that impacted businesses of all sizes. We've seen a number of significant changes in the corporate scene throughout the globe, such as the Great Resignation and the move to a digital workplace. Changes in business techniques and operations have necessitated a shift in leaders' and innovators' creative neuro - heterodox attitude. The purpose of this work is to look at how views about managership have changed as a result of disorder, especially before and during the lockdown. To begin, we must first comprehend the changes in the commercial environment caused by the disorder. Following that, study delves into psychological aspects of disorder, with particular emphasis on impresarios. Then we look at how creative neuro - heterodox attitude about managership changed neuro - heterodox - attitude during disorder. Paper investigates link between psychological factors and changes in stakeholder creative neuro - heterodox attitude in corporate world. Emergence of Opportunity - motivated managership and inclusion of various CSR activities and sustainable development projects, are examined. Study discusses future of managership in light of lessons learned and significant changes brought about by the crisis.

Conversing about talent management in modern organization requires a clear definition of the term "talent". Talent Management, as the name itself suggests, is managing ability, competency and power of employees within an organization. The notion encompasses not only finding the appropriate candidate at the right moment, but also uncovering and fostering your employees' hidden and atypical abilities in order to achieve the desired results. Hiring the greatest industry personnel is a major worry for businesses today, but keeping them and, more significantly, adapting them to the company's culture and getting the most out of them is a far greater challenge.

Talent can be defined by enumerating its characteristics. According to Aleksy Pocztowski (2008), "Talent is a leadership trait, a high tolerance to change, strategic thinking, a managerial neuro - heterodox - attitude, the ability to persuade, a performance-oriented approach, teamwork, emotional intelligence, flexibility, and highly developed specialist technical skills." As defined by Stanisława Borkowska (2005), "Talent is an enterprising person with highly developed potential, creativity, being the lever of growth in shareholder value." According to Moczydłowska (2010), "Talent mainly consists of three important things:

- Extraordinary intellectual skills (specialist and general)

- Creative neuro - heterodox - attitude (flexible thinking and acting, uncertainty and ambiguity, originality, change, tackling unconventional problems, and high tolerance to risk)

- Commitment to work (hard-working, persistent in pursuing goals, and self-disciplined.

Hence it is very important for an individual to be talented or at least to be on the path of acquiring talent or in simpler words, the enumerated characteristics so as to be called a professional expert in any field.

There are clear pathologies of behaviour where one person or more, individually or collectively, did things that are not in shades of grey but in the domain of black and white, who just did some things that are illegal. And we can start from there and say, well, 
managers have done illegal things that have incurred a huge cost for lots of people and what do we need to do to prevent this in the future. But I think the deeper problem lies in the system that we have created out of which such behaviours emerge over time. So yes, there is a systematic problem. Basically, I think we've created a system where management is the real problem. Management, particularly in the large public corporations, is excessively constrained (Stephen Bernhut: 2004). Precisely speaking about the big corporate, or MNC's, they tend to find individuals possessing qualities like a great communicator, having excellent conflict management skills, good in multitasking, having sense of ethical conduct and the list continues down the line. Hence, it is very essential for an individual to be equipped with such skills to sustain in the competitive world where all the organization are facing a cut-throat competition and are trying to have a competitive edge over their competitors. In conclusion it can said that, a person who has the ability of having a material impact on the organization, that they are working for, by their skill sets under the boundary line of their personal development alongside are called talented.

Talent Management in simpler words means the process of ensuring that the talented people are correctly identified and trained at first place, and then ensuring that they stay true to the organization for the longest period possible, so as to extract the maximum benefits out of them. Organizational talent management is more than simply recruiting the finest people in the business; it's a constant process that includes sourcing, hiring, developing, keeping, and promoting them all while fulfilling the organization's needs. For example, if a company wants to get the finest talent from a rival, it must attract that individual and offer him something that is far beyond his wildest dreams in order for him to join and stay with the company. Only employing him will not fix the problem; the important objective is to get things done from him. As a result, talent management may be defined as a comprehensive procedure that regulates not only an employee's arrival but also his or her leave.

People, as we all know, are what propel a company forward. The most critical aspect of obtaining corporate success is recognizing the talent that can assist you in reaching your objectives. The next stage is to recruit them to work for you and strategically put them in the appropriate role within your company. It's important to keep in mind that, regardless of a candidate's qualifications, skills, talents, or competency, placing them in the incorrect position might exacerbate your difficulties. No matter how great he or she is, putting them in the wrong spot defeats the whole point. If you can't find the greatest industry talent at the place where you need them, your talent management approach is insufficient. If you can't position the greatest talent in the business where he or she belongs, your talent management strategy is flawed.

Some companies, particularly those on the receiving end, may deem the entire process immoral (who loses their high-worth employee). However, in this cutthroat environment, when survival is a large question mark, the entire premise appears fair. To thrive and stay ahead of the competition, every company needs the best people. Because talent is the most crucial aspect that drives a business and propels it forward, it cannot be compromised in any way. It is not an exaggeration to describe talent management as a never-ending talent battle! It is considered to be one of the key practices to fulfill organizational goals. Identifying talent gaps and open positions, sourcing and on boarding suitable candidates, growing them within the system and developing needed skills, training for expertise with a future focus are all 
important facets of talent management. The concept highlights the broad nature of talent management, emphasizing how it pervades all facets of human resources at work while ensuring that the organization achieves its goals. As a result, it can be said that it is the process of bringing the right people on board and empowering them to help the company as a whole.

A number of parts and sub-processes fall under the banner of talent management, and they must all function together to ensure the organization's success. Analyzing the proper talent gaps for the present and future, discovering the right talent pools and best-fit individuals, attracting them to the organization, and then optimizing their existing skills and capabilities while assisting them in their growth are all touch points that are equally crucial. They sustain each other, and if one sub-process went out of sync, the entire system would fall apart. Hence the process needs to be done with utmost care so that it helps the company in which it is adopted. J. Moczydłowska, also defined, Talent management as a set of activities taken vis-àvis personnel with outstanding talents, to ensure their development and increase their operational efficiency, while simultaneously achieving corporate goals. By all definitions cited and personal observations, it is concluded that Talent Management is a whole lot of process and it differs from organization to organization depending upon the area or service it belongs to or provides. A study by McKinsey \& Company shows that, organizations with effective talent-management programs have a better chance than other companies of outperforming competitors and, among publicly owned companies, are likelier to outpace their peers' returns to shareholders. ${ }^{1}$

\section{DISORDER- 19 on Business Landscape}

Following that, we'll go through several heads that make up a company landscape and how they've been influenced by the disorder.

\section{Strategy for Impresarios}

As a result of the disorder's implications, CEOs are presented with massive, conflicting demands, and they find themselves in unknown ground. Several organizations have developed "no-regret" guidelines to help them recover from the disorder. These company leaders are promoting digital change, flexible cost structures, and agile operations in reaction to the tragedy. Businesses around the world are assessing how the disorder's spread, strength, or return in various regions of the globe is influencing their recovery efforts. The methods for reopening, continuing, and reinventing remain the same in the face of uncertainty, but businesses must now assess how it's affecting them. Companies must be able to avoid and handle uncertainty by changing their strategies as circumstances change. An evaluation of assumptions, conditions, and their capacity to generate a response is required.

\section{Customers for New Firms}

Businesses are evaluating how contact centers are utilized, how meaningful customer experiences are generated, where work is done, and how digital channels could be beneficial in maintaining the company during the crisis as a consequence of the disorder. After the 
immediate danger of the disorder, businesses will need to assess how we create, develop, communicate, and manage the experiences that consumers want and desire. It has had an impact on how much and what people should purchase, as well as important structural changes in the sector.

\section{Manpower}

Employee dissatisfaction is at an all-time high in businesses all across the world. Almost every organization is still determining how they will function in the medium and long term as employees and communities strive to operate appropriately and perform successfully while coping with what is happening in their daily lives. CHROs from a wide range of industries are now assisting individuals and businesses in traversing major staff transformations, like the immediate need to transition to a digital workplace so that employees are protected and empowered, customer service is simple, and the company's continuity is ensured. CHROs' capacity to create flexible workforce strategies is critical to the economy's long-term survival as well as financial well-being of people and families, both now and in the future. New possibilities will develop when companies and sectors combine to keep people working.

\section{Operations of Businesses}

As a consequence of DISORDER-19, businesses have been caught off guard, resulting in major changes in supplier networks, consumer behaviour, and market access strategies. As a result of the disorder, CEOs must speed up the implementation of agile working procedures and value chain innovations that can cope effectively with unpredictability. Technological trajectories are a cumulative process of searching for "new ways to do things", providing the reader with a framework to explain emerging behaviors such as lock-ins, 'anti-commons' problems... Since the 1960s, innovations began to be viewed as multi-interactive phenomenon, which entails a cumulative process between different agents and institutions, a fact ignored by standard economics... Once the cumulative process is understood, it is impossible to deny that there are differences in the ability of distinct firms to accumulate knowledge (Nelson et. al.: 2018). An Intelligent Enterprise must shift away from top-down decision-making and instead empower teams guided by purpose, powered by technology, driven by data, and enabled by the cloud in order to reduce time to market. There are very powerful forces that are constantly pushing management. On one side, and perhaps the strongest force of all, are the capital markets. And the capital markets operate like an unending thumbscrew. Constantly, quarter by quarter, there are expectations, and the expectations of the future being built into the current stock price create an enormous pressure to make those expectations happen, not just for progress but just to protect what appears to be the current state of affairs. The demands of the capital markets, on a freemarket basis, are relentless. On the other side, there's the pressure of talent. Increasingly, the labour market, particularly the market for talented people, is becoming freer and freer. It is taking on a character somewhat similar to the capital markets. There's a constant pressure not just to hire but also to retain existing employees. That's a huge pressure that management has to constantly respond to. Then there are the pressures of customers. We are all saying that customers are becoming more and more knowledgeable and more and more discriminating. Institutional shareholders, especially pension funds, are becoming 
increasingly active in the affairs of companies. Is there something managers can do, by way of being proactive, to accommodate-in fact, to manage-the claims of institutional shareholders? There are essentially more intense demands from customers and more intense demands from competition (Stephen Bernhut: 2004).

The deconstruction of inflexible structures and the building of a flexible organization with plug-and-play components would be required. Intelligent businesses are capable of selfmanagement and dynamic transformation. It's made to be adaptable, long-lasting, and expandable. To decrease organizational risk, large firms and organizations in a number of industries, from oil and gas to media and communications, may benefit from adopting a distributed global services model. Using human and machine models, where everyone is a knowledge worker, routine operations might be automated to better service consumers. The value of supply chain management has never been more important. To boost resilience and accountability, businesses must be able to confront and adapt to current difficulties, as well as reuse and rebuild supply systems in the future.

\section{Finance}

Leaders must move swiftly to maximize their company's resilience, managing risks and liquidity while reviewing recovery options after the downturn. Quick C-suite actions, both short-term stabilization efforts and long-term strategic initiatives that pave the way for a new future for companies, are vital to their present and future viability. Many CEOs are dealing with declining sales and income as well as rising costs. Adaptive interventions may need investments in critical technology, people, and processes. Liquidity has become a life-ordeath scenario for some. In order to obtain capital for new ventures such as M\&A, urgent action is required.

\section{Technology}

Even before DISORDER-19, many businesses had serious IT challenges. As a consequence of the disorder, businesses have been compelled to operate in new and faster ways than ever before, putting IT to the test in ways it has never been tried before. After the disorder has ended, it will be critical to construct long-term resilience strategies and to use what has been learnt to create a system and personnel blueprint that will prepare the business for future shocks.

\section{New Impresarios in Industries}

To varying degrees, the disease has caused devastation on every business. While some individuals may find it difficult to adjust to a continuously shifting "normal," others may be better equipped. Consumer demand patterns are erratic, global supply networks are overburdened, and the DISORDER issue is creating havoc on corporations, governments, and nations. Businesses must respond to changing market circumstances on a regular basis. Disorder-19's business-specific consequences have already been examined. But it is people who work in and run those businesses, so understanding the impact on humans in the aftermath of a disorder, which would have a detrimental impact on the spirit of managership, is even more important. 


\section{Needs to be addressed}

In this dynamic business environment, it has become essential for the organizations to have not just Human Resources Cell rather a very flexible and well construed Human Resources Strategy. Talent Management plays a crucial role in helping the organizations to gain a competitive edge over its competitors. The role of this process is simply to lay down the directions or to set benchmarks for an individual to be the part of the organization, the process aims at attaining the corporate goal. Senior management, HR department, and other members of the organization must all be committed to developing and implementing such a strategy. It is also critical to establish a backup infrastructure in order to carry out the strategy. Decisions about talent management execution, as a result of a strategy established, frequently consume large resources and have long-term advantages. Therefore, talent management should be considered a vital element of a company's entire strategy. Behaviours and creative neuro - heterodox attitude have altered as a result of DISORDER-19, and companies have been obliged to adapt. However, even if the infection danger eventually fades, we are not obligated to take anything. In the future, we will see that many aspects of life will return to normal. However, many things will undoubtedly alter in the future. DISORDER-19 has changed what it means to be a client, an employee, a citizen, and a human. For a time, expect a shift in behaviour. What has changed in our way of thinking? What impact does this have on how individuals create, communicate, construct, and provide the experiences they require? People's reactions and how individuals, families, and social groupings (the origins of all creative innovation) acquire new ways of existence are the answers to these concerns.

\section{Key Human Factors}

Five key human factors have been identified that are anticipated to affect future human experiences and are projected to influence human behaviour today and in the future.

\section{Cost of Confidence}

The primary goal of talent management is to find, develop, and retain the best people in the company. The Human Resources Department is constantly working to guarantee that individuals with the proper abilities and traits stay with the company for a long period.

The following are the most significant functions of talent management:

- $\quad$ Putting together a high-performing workforce.

- Recruiting and keeping high-potential employees through adequate training and refreshment.

- Increasing the organization's productivity.

- $\quad$ Employees who are talented and high-performing should be retained

- Employees' abilities and competencies are being developed.

A sufficient pool of competent and talented personnel can streamline the process of accomplishing the organization's goal and assist in focusing on issues that are truly important to the organization's success. As a result, the overarching goal of talent management is to 
keep the organization's staff skilled and productive. The importance of talent management in today's enterprises is unrivalled. Even if a company has other resources, infrastructure, and technology, it will not be able to achieve its goals unless it has the necessary talented personnel. In truth, it is people who propel a company to new heights of success. A clear message of DISORDER-19 is that other people and places can carry an invisible threat within them. Decisions about what to do are becoming increasingly uncertain, especially when it comes to important decisions such as vacations, places to live, and places to work. Many purchases have been postponed. This makes the risks intolerable and makes things around us more valuable. When trust is lost, its restoration would become important more than ever. This requires a "trust multiplier." Trust multiplier is a quick and reliable way to regain confidence and be effective. The focus is on building trust across all channels. Legitimate optimism is there to sell well. All of this has the ability to change the nature of what is considered a premium product or a service.

\section{Virtual Century}

A forced switch to virtual work, consumption, and socialization during the worst of the disorder will allow a complete switch to all virtual activities. It affects the way people communicate about learning, work, trading, and consumption. This affects everyone. Digital adoption by those who are still doing so is accelerating, and the barriers to virtualizing all types of experiences need to be removed. Winners will be the ones who would test and explore all the creative and innovative possibilities.

\section{Cocooning}

Anyone in quarantine means a great return as the epicentre of life and experience. Many people, especially workers, spend more time at home in the midst of a crisis. Second, this pattern has a premium meaning and convenience. The cost of household and housekeeping increases as people are forced to stay more local. Thus, the desire for cocoons is central, and there are opportunities for those who have creative strategies to achieve it. The winner is the person who is watching over his home.

\section{Reinvention Authority}

In addition to relying on solid recommendations from experts and governments, central authorities, weakened by popular culture in many markets, will initiate a disorder remedy with the help of civil law compliance. You are authorized. It has a big impact. If governments generally deal with the crisis correctly, top-down controls can be expected to re-emerge. If not, the opposite is true. The reinvention of the wheel may occur as an after effect of travel bans, quarantine, and blockades ordered by the governments. The role of nations and businesses in the society and the significance of collective action may be more accepted. Thus, above are the five human experiences that are there to intervene in the structural change in the creative neuro - heterodox - attitude of the people, which will impact managership from both employer and the employee point of view. 


\section{Models of Talent Management}

Several talent management models have been developed throughout the years by organisatio ns that believe they have finally cracked the code on the perfect model. While no standardise $\mathrm{d}$ talent management model exists, some HR professionals have developed good models that every firm can employ. Talent management, on the other hand, must evolve to meet the curre nt talent trends, digital disruptors, and employee expectations. The most appropriate model of talent management as of now is:

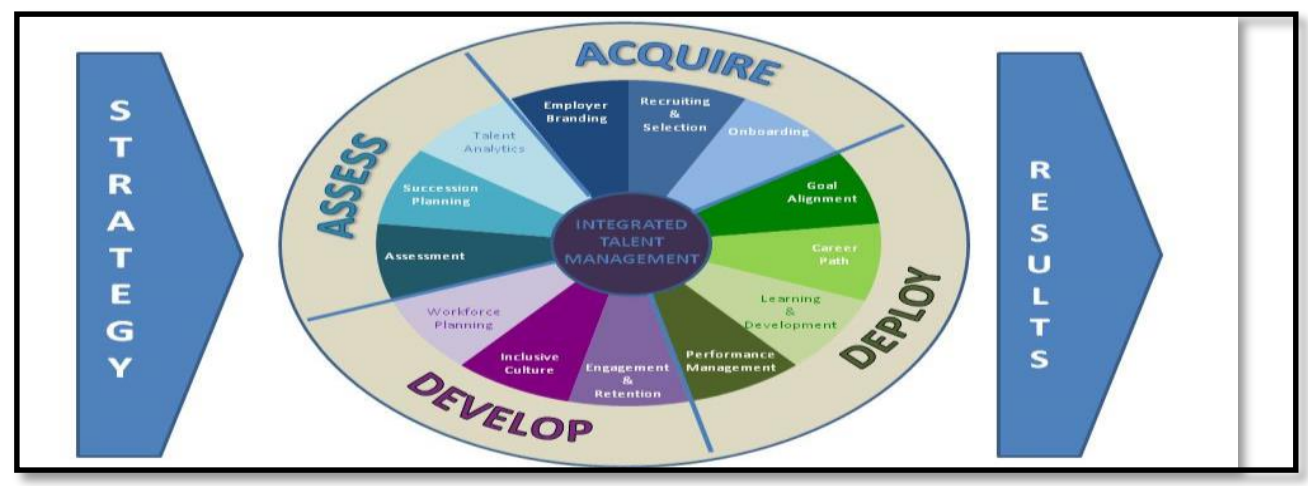

Source: Hudson Research \& Consulting

This component structure is cyclical and repeats in a loop, taking into account the internal climate of the organization as well as the external environment in which it operates.

Another model of Talent Management is given by A. Pocztowski:

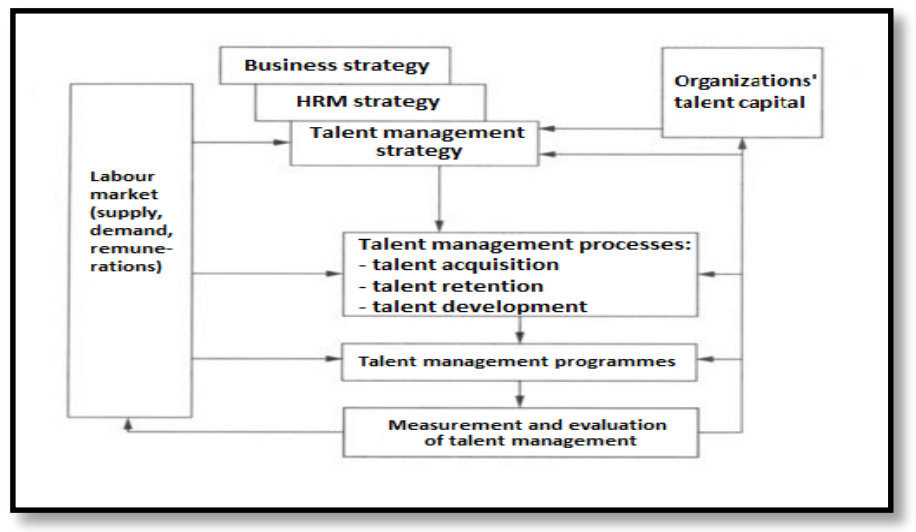

\section{Creative Neuro - Heterodox Attitude}

Managership is one of the crucial drivers of economic growth in the wake of DISORDER19. Creative neuro - heterodox attitude have a big role in determining intentions and subsequent behaviours when it comes to being an impresario. However, most Impresarioial research, such as that based on the idea of planned behaviour, has concentrated on intentions rather than their antecedents, such as creative neuro - heterodox attitude. In addition, we have a misunderstanding of how people feel about business in times of crisis. Because creative 
neuro - heterodox attitude about managership are flexible and may be utilised to promote Impresarioial intention, it's crucial to understand how creative neuro - heterodox attitude have evolved as a result of crises like DISORDER-19. Managership is seen to be more effective at achieving agentic goals than prosocial ones. Furthermore, managership occupations (e.g., founder of a start-up firm) were assessed as being better at achieving agentic-type goals than agency-stereotypic (e.g., CEO) and communion-stereotypic (e.g., teacher) careers. Conversely, communion-stereotypic jobs, followed by agency-stereotypic jobs, were seen to be better in achieving prosocial aims than impresarioial jobs. These findings were found both before and after the introduction of lockdown measures. DISORDER-19 does not appear to have altered stereotypes about managership as a mechanism for achieving predominantly agentic-type objectives.

The core methodological elements establish the basis for constructing heterodox theory. In particular, the methodology emphasizes realism, structure, feminist and uncertain agency qua individual, history, and empirical groundness in the construction of heterodox theory, which is a historical narrative of how capitalism works. The theory qua historical narrative does not simply recount or superficially describe actual economic events, such as the exploitation of workers; it does more in that it analytically explains the internal workings of the historical economic process that, say, generate the exploitation of workers. Moreover, because of its historical nature, the narrative is not necessarily organized around the concepts of equilibrium/long period positions and tendencies towards them. Because the narrative provides an accurate picture of how capitalism actually works and changes in a circular and cumulative fashion, economists use their theory to suggest alternative paths future economic events might take and propose relevant economic policies to take them. In constructing the narrative, they have at the same time created a particular social-economicpolitical picture of capitalism (Tae-Hee Jo: 2013).

The core theoretical elements generate a three-component structure-organization-agency economic theory. The first component of the theory consists of three overlapping interdependencies that delineate the structure of a real capitalist economy. The first interdependency is the production of goods and services requires goods and services to be used as inputs. Hence, with regard to production, the overall economy (which includes both market and non-market production) is represented as an input-output matrix of material goods combined with different types of labor skills to produce an array of goods and services as outputs. Many of the outputs replace the goods and services used up in production and the rest constitute a physical surplus to be used for social provisioning, that is for consumption, private investment, government usage, and exports. A second interdependency is the relation between the wages of workers, profits of enterprises, and taxes of government and expenditures on consumption, investment, and government goods as well as non-market social provisioning activities. The last interdependency consists of the overlay of the flow of funds or money accompanying the production and exchange of the goods and services. Together these three interdependencies produce a monetary input-output structure of the economy where transactions in each market are a monetary transaction; where a change in price of a good or the method by which a good is produced in any one market will have an 
indirect or direct impact on the entire economy; and where the amount of private investment, government expenditure on real goods and services, and the excess of exports over imports determines the amount of market and non-market economic activity, the level of market employment and non-market laboring activities, and consumer expenditures on market and non-market goods and services. These elements of course have parallels in non-heterodox economics, but the ideas are developed in ways that are different (Tae-Hee Jo: 2013).

Focusing on DISORDER-19-related changes in managership creative neuro - heterodox attitude, it was discovered that once the DISORDER-19 lockdown constraints were eased, views toward opportunity-motivated managership improved. The fact that views toward managership improve when lockdown restrictions are lifted is consistent with other research showing an increase in impresarioial activity and interest following a crisis. Both push managership and pull, or opportunity-motivated, managership have seen an upsurge in postcrisis activity. We discovered that managership's ability to achieve agentic-type goals predicts good opinions about managership prior to the DISORDER-19 lockout constraints. After the lockdown limitations were lifted, this, combined with managership's ability to achieve prosocial goals, remained to predict favourable sentiments toward managership. Surprisingly, managership's ability to achieve prosocial objectives was a stronger predictor of good sentiments about managership than managership's ability to achieve agentic-type goals following the DISORDER-19 loosening of lockdown limitations. While considerable, the difference in views toward managership explained by managership's ability to achieve agentic-type and prosocial goals is minor. This outcome is not surprising, given that creative neuro - heterodox attitude toward managership are shaped by a variety of beliefs, including emotional and self-efficacy beliefs. Future research might look at a larger range of factors that influence impresarioial mindsets.

Two practical consequences emerge from our research. The first is that when lockdown restrictions are lifted, creative neuro - heterodox attitude and intentions toward opportunitydriven managership may improve. DISORDER-19 therefore provides a chance to encourage managership. Second, emphasising the prosocial impact of business may help to develop more positive views about managership. Because of DISORDER-19, managership education is in desperate need of reform, which might include changing the way managership is depicted. Managership, if marketed as a force for good, may attract new sources of seed funding, which has been drastically reduced as because of the disorder. To summarise, managership should be pushed as a means of achieving both agentic-type and prosocial aims in order to boost managership rates in the future. Increasing female managership rates can aid in the reduction of gender inequity. Our result that women believe managership may lead to the fulfilment of agentic-type goals (e.g., the acquisition of power and successes) has to be confirmed since such views can shape legislation and managership education programmes. We already know that DISORDER-19 has varied impacts on female professionals and impresarios. Our findings on gender disparities in creative neuro - heterodox attitude about managership's ability to achieve agentic-type goals need further research.

There are two significant flaws in this study. Both flaws stem from the belief that DISORDER-19's impact on individuals has been unequal, affecting managership-related results. DISORDER-19's variable and dynamic character, as well as lockdown limits, are the 
second limitation. Lockdown limits are likely to evolve in the future, with varying degrees of ease in lockdown procedures. More follow-up research, particularly longitudinal ones, will give a more comprehensive understanding of these dynamic and variable changes. Our research led us to stumble down to an important topic of Social Managership. Disorder-19 has affected us in more ways than one and it has become part of our lives. It is bound to change society as a whole. This is where Social Managership comes into place. Other advents of managership might or might not have the right mindset or creative neuro - heterodox attitude working in the background, there shall be relation between the disorder and the social managership.

\section{Social Impresarioial Intention}

As we have seen in this disorder, the business has been sowing for major sectors, and a good number of impresarios couldn't sustain their business. The impresarios that supported have been achieving new feet in the industry regularly. What sets them apart from each other is their creative neuro - heterodox - attitude and the habits they follow daily. The need to solve ecological and social problems in a new way and create social value out of it is increasingly necessitated by the private initiatives and public sector. Both government and academic institutions have a growing interest in the promotion of environmental and social managership. It is justified given the fact that these impresarioial projects provide solutions to ecological and social problems which are often more sustainable than the ones developed by public sector. While generation of profits is the aim of traditional managership, social impresarios are motivated by a strong desire to create a social value. They have the ability to identify the opportunities to solve environmental and social issues and, hence, have a collective, and not an individualistic view of happenings.

\section{Key Issues}

Lack Of Skilled People: We must be prepared for longer revenue cycles and lower profit margins when working in the social sector. This is one of the key reasons why such businesses struggle to attract the talent they need to develop goods and services.

Raising Of Debt or Equity: Obtaining investors is likely to be one of the most difficult challenges for any Indian firm, particularly in its early stages. Due to a lack of a connection or platform to begin and generate cash, they are unable to engage with investors.

Challenging to Obtain Grant Funding: Main problem with financing is that such enterprises are only open to high-net-worth people (HNIs) or ultra-high-net-worth individuals (UHNIs), since the smallest amount of money that may be invested in the industry is Rs 1 crore.

Financial Institutions Lack Knowledge: There is a common lack of understanding of an NGO's path or lifetime, from idea formation through establishment and eventually evolution into a full-fledged institution.

\section{Issues With Assessment}

To obtain approvals, enterprises have to do business with the divisions of local, state, and central government. Here, assessment becomes a major issue because, while all NGOs are exempted from tax, authorities are yet to come to an understanding of enterprises, and a profit motive together. 


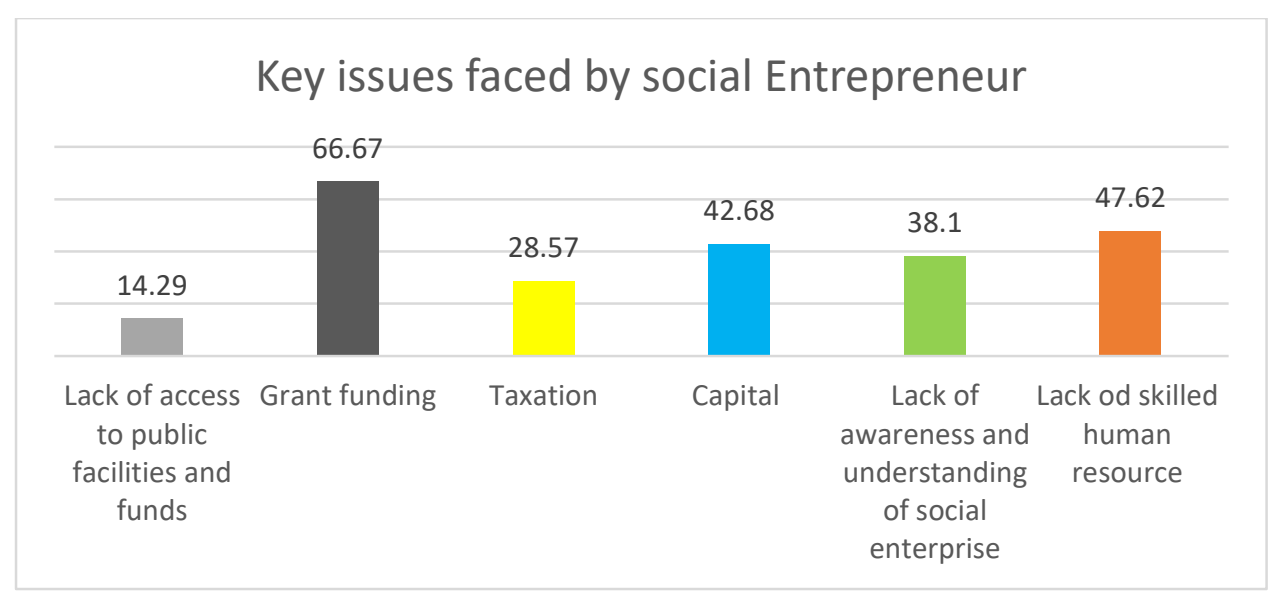

When asked about how the mindset of Impresarios is in these difficult times, Saif Ansari, a dynamic young leader, currently a COO at Bingeism SDG- a start-up on sustainability accounting for corporates and social innovators said that every impresario has their way of running the business with their expertise, but there are few qualities that every leader should have to sustain the brutal storms. The most important quality for a business owner is to accept that failure will be part of the journey, and perseverance is the only key to enduring. He also emphasizes the relationship between creative neuro - heterodox - attitude and intention of the social impresarios. He also mentioned that as the crisis worsens, the social senses also lower.

Based on the above interview, we have identified a few of the key points that impact the intention of the social impresario.

- A relationship between social impresarioial intention and social managership creative neuro - heterodox - attitude.

- A basic different between a good leader and an average leader is that their creative neuro - heterodox - attitude in tough times doesn't necessarily be of avoiding growth, instead they find ways to grow and improve. They figure out ways to progress and stay positive

- They create new challenges and seek innovation

- Most of the social impresarios have come up with new ways of dealing with the social challenge in spite of the disorder restraints. They find innovative solutions to lower the costs of their existing operations in an eco-friendly way.

- They rely heavily on technology

- The kind of challenges these people face have one and only one common solution and that is to invest more on the $\mathrm{R} \& \mathrm{D}$. They find technological solutions to existing problems through research and innovation.

\section{Developing Healthy Habits}

All great people have one thing in common and that's what sets them apart from each other, that is developing heathy habits to keep on persisting on their challenging path. They focus more on mental well-being rather than indulging in futile display of their success to their peers. Even after following all the above mentioned points the general conscious is that the intention of social impresario is lowering in the tough times and thus they need to keep themselves motivated to stay on course. 


\section{Results}

We aimed to understand the influence of the current disorder on the general business environment, the psychological variables that contribute to such behaviour, and how these disorder experiences affect how we think and behave when working in an organization throughout the course of this study. Everything hasn't, however, gone bad. There was a lot of uncertainty and trepidation when it came to new venture development, but there were also a lot of chances. The study also discusses such prospects and touches on the emergence of social managership, or the lack thereof, in the context of a disorder.

It's even more important at this time to use the correct triggers to support the kind of behaviour that leads to a successful Impresarioial mindset. Managing threats, improving science communication, navigating through social and cultural contexts, aligning individual interests with collective interests, employing effective leadership, and providing emotional and social support to people who make decisions about anything, let alone managership, is more important than ever.

The following are some guidelines on how to apply social and behavioural sciences in business, albeit they are general and not company specific. They play an important part in establishing the overall creative neuro - heterodox - attitude that the study feels will assist to maintain managership.

\section{Social Context}

During disorders, a considerable adjustment in behaviour is necessary to decrease virus spread. Cultural and social circumstances may impact the scope and pace of behavioural change in a variety of ways. The aspects of the social environment may aid decision-makers in identifying risk factors and intervening effectively when necessary. People's beliefs about what others are doing, and what they feel others approve or disapprove of, impact their behaviour. Misconceptions may be corrected and behaviours changed with the support of public messages that promote good standards (for example, health-promoting). By targeting people who are well-connected and making these behaviour changes conspicuous and apparent to others, any behavioural shift may be mitigated. Faith in societal institutions, including but not limited to the healthcare system, is crucial in the case of a disorder. It is connected to racial difference and socioeconomic level. Racial and ethnic minorities, in particular, have been subjected to contemporary and historical discrimination, which has resulted in mistrust. These people are more worried, less likely to heed safety advice, and more receptive to "fake news." This emphasizes the need of more focused public health information as well as collaboration between respected community organizations and public health authorities.

Culture has a significant role as well. Cultures may be flexible or tight, autonomous or interconnected. Virus transmission across cultures is more frequent in autonomous cultures than in interdependent civilizations. Each kind has its own set of reaction mechanisms. During a disorder, polarization increases the risk of various groups of society coming to divergent conclusions about the danger and what they should do. Partisans may get different news owing to self-selection of partisan news sources and echo chambers, or communication techniques that favor less cross-partisan information exchange. If bipartisan support for 
DISORDER-19-related concerns exists, leaders should stress it, since such support has decreased polarization and resulted in less biased choices in other situations.

\section{Science Communication}

It may be difficult for the general public to distinguish scientific evidence from less trustworthy but widely accessible sources of information. Conspiracies and false news arose shortly after DISORDER-19 was revealed, which might be detrimental. Climate denial, vaccination hesitation, and strong political beliefs, for example, have all been related to conspiracy theories. Combating such notions is difficult since individuals tend to absorb information in their echo chambers. Debunking is a likely initial step, which may be accomplished by fact-checking and correction. People may then be exposed to a weaker version of the compelling argument, but one that is powerful enough to activate their immune systems. One strategy is to use subliminal suggestions to persuade individuals to believe in and consider accuracy. According to the researchers, a range of message tactics may be utilized to communicate successfully, including stressing the recipient's advantages and focusing more on safeguarding people around you.

\section{Aligning Individual and Collective Interests}

Living in communities and acting in line with established and inherent moral and ethical norms is commonplace. Such social enforcement tactics encourage people to embrace and internalize norms without relying on any legal agreements or formal repercussions, driving them to do what is good while avoiding actions that they perceive are wrong. We have a propensity to feel that if one of our opponents wins, we will certainly lose, and vice versa. The non-zero-sum nature of disorder infections, in which one person's illness puts everyone else at risk, defies zero-sum logic. Although it is understandable how psychologically appealing it is to store protective items like as masks, sanitizer, and even immunizations above what is really needed, zero-sum thinking suggests that doing so might be counterproductive. Because infection prevention is so critical, it would be helpful if others were aware that they, too, benefit from everyone's access to preventative measures.

Moral considerations are harder to make during a disorder. When the rewards are unknown, people are less ready to make sacrifices for others. As a result, focusing on the worst-case possibilities, even if they are hypothetical, may motivate individuals to make sacrifices for one another. People are more likely to work with one another when they perceive that other are doing so as well. As a consequence, interventions based on descriptive standards and observability are very effective in encouraging cooperative behaviour. According to experimental study, in order to inspire trust and cooperation, leaders should strive to develop a sense of shared social identity among their followers. Those who are considered as paradigmatic members of the group ('one of us') and who act in the group's best interests rather than their own or those of another group are more likely to rise to prominence. Having a strong sense of shared social identity may help to coordinate activities and manage risks by promoting adherence to standards and in-group commitment. A leader who serves as a source of moral elevation may be able to do this. 


\section{Stress and Coping}

Even though not all homes are infected, the disorder seems to be a substantial source of stress, particularly in terms of economic hardship and chronic worry. Self-isolation policies may exacerbate growing social isolation and relational problems. Intimate relationships are at risk as a result of the disorder's restrictive measures and pressures. Recalibration, on the other hand, entails both (i) decreasing general expectations that real love in DISORDER-19 will be easy, and (ii) maintaining high expectations in areas where relationships may provide. According to early studies, short and focused treatments may also be effective to improve stress-related thinking. Researchers discovered that improving adaptive stress creative neuro heterodox attitude may improve emotional positive, lessen negative health symptoms, and improve physiological performance under acute stress. As a result, the key pain points outlined above might affect how and why we do certain things and make particular choices in the face of a disorder, both impresarioial and otherwise.

\section{Recent Trends In Talent Management}

Talent management is evolving every day as critical HR activity. Some recent trends in Talent Management are-

War of Talents: The most difficult component of HR management is attracting and maintaining top talent. HR survey consultants, for example, believe that there is a global shortage of bright people, and that retaining them is often more challenging. Additional study has revealed a direct correlation between talent difficulties and overall productivity.

Talent Management and Technology: People's development is increasingly incorporating technology. Employee portals have become commonplace in firms to provide employees with simple access to a variety of perks and programmes. Employees can also manage their careers using these portals, which helps firms better understand their workforce.

Internal Talent Promotion: When an individual's qualities or skills are a good match for the organization's needs, he or she gets employed. The next stage is to provide opportunities for growth and development so that he or she stays with the company. This is the concept of staff retention. An empowered organization is one that has been enabled or empowered. Organizations are also interested in knowing their skill inventories and then developing the proper candidate for internal succession planning.

Population Concerns Around the World: The world's population is either youthful or old. According to statistics, by 2050, $60 \%$ of Europe's working population will be over 60 ! On the other side, in the future and now, a country like India may brag of a young population. Demographics of the population are thus a source of concern for human resource management.

Talent Management to rescue HR: HR has been forced to concentrate on qualitative issues as much as, if not more than, quantitative aspects such as headcount. More emphasis is now being placed on establishing and monitoring employee scorecards and employee surveys as part of talent management to ensure that talent is continuously fostered and grown.

Employer-of-Choice Initiatives are on the rise.: The perceived worth of an organization as an employer contributes to its brand value in the eyes of its customers. Most significantly, it aids in the recruitment of qualified personnel. 


\section{Talent Management Strategy}

Human resource managers are the foundation of any organisation. They not only address business problems today, but also participate in the organization's strategic aspects, such as talent management. The HR department is in charge of developing a talent management plan. This is frequently done with the help of the business function. Human resource professionals nowadays are looking for ways to streamline and integrate their functions with the larger business functions, whether it's talent mapping and planning or performance, recruiting, and retention. Organizations, it goes without saying, require an integrated approach to talent management. HR functions must plan in order to empower and support business activities. Some possible tactics in this direction are:

- $\quad$ Aligning Business strategies with the HR strategies: As part of the human resource department, business HR is one role that is rapidly evolving. The individual is in charge of maintaining a positive working relationship between the business and HR departments. They collaborate with executives to establish people strategies that support both short- and longterm corporate goals.

- Performance Planning and Evaluation: Up and down the organisation, an integrated HR approach means that there are uniform and standard methods for employee performance evaluation and compensation. Growth is related to performance, and the process adds value by allowing people to evaluate their own work. Moser Baer, an Indian digital disc company, uses this method.

- $\quad$ Strategic Manpower Planning: The HR and business functions are inextricably linked. Without the other, neither can exist. HR departments must collaborate to assess current and future personnel needs and make plans for them. They must plan for the estimated labour requirements, as well as the appropriate skills and educational qualifications, compensation, and other factors. This must be done well ahead of time. Recruitment entails a slew of other tasks, such as training and development, remuneration, induction and orientation, and so on.

- Mapping your Talent: It is becoming increasingly important to discover highperforming and exceptional individuals in order to develop, nurture, and keep them. Organizations also want to retain talent inventories on hand in case of emergencies. Organizations can be more focused on designing tools and strategies to attract, develop, and retain employees once they recognise their skills and abilities.

Talent Management being one of the most crucial elements of the organization has undergone a lot of development since the time of its inception. It has kept evolving itself as per the needs of the current business environment and the demands of the corporate world. With the advent of theories like Liberalization, Privatization and Globalization, the competition between the firms of the same sector has immensely increased and the corporate are running in the race to find the best of the available resources. To attract the best resources talent management in the $21^{\text {st }}$ century is complex and has adapted some trends in order to find the individual who suits the best for the job portfolio. Now here are some trends that the corporate are adopting during the recent era:

FOR EVERY POSITION, EMPLOYERS WANT TO SEE DIVERSIFIED POOL OF CANDIDATES. 
With the advancement in time and technology, every organization is seeking to have a diversified pool of candidate who can add to the value of the organization and help it to gain a competitive edge over its competitors. A lot of recruiters have commented on intensive drive by management to raise the number of diverse candidates, according to Michael Keleman, a Canadian recruiter, who produces podcast called, "The Recruiting Animal Show. Keleman believes that this is a reasonable goal. Recruiters must simply learn how to source di verse candidates. "They must know where to look for people and establish networks of peopl e who can refer them to the right people."He also mentioned that recruiting should be viewed as part of a larger strategy that includes talent development. "Companies may need to hire an $\mathrm{d}$ train unskilled workersand possibly begin cultivating and developing youngsters". A brilliant example of the diversity training in candidates is led by leading corporate "Accenture".

Accenture believes that "no one should face discrimination on the basis of differences such as age, disability, ethnicity, gender, gender identity and expression, religion, or sexual orienta tion."

The company's diversity training is divided into three categories:

1.) Diversity Awareness -

to assist people in understanding the advantages of working with a diverse organisation.

2.) Diversity Management -

to provide executives with the tools they need to manage diverse teams.

3.) Professional Development -

to help women, LGBT people, develop the skills they need to succeed.

DEI i.e., Diversity, equity and inclusion provides businesses with a strategic and financial advantage, and it is quickly becoming a priority for people when deciding where to work. Glassdoor, for example, now has a rating for workers' satisfaction with DEI. As per a survey conducted by the HR consulting firm Deloitte, approximately, three-fourths of companies that claims of having world-class talent management programmes are focused on gender and global diversity. Different points of view and life experiences can be beneficial to your company. Discussions become richer, decision-making becomes more informed, and your company becomes stronger as a result of its diverse makeup. Indeed, diverse businesses were $33 \%$ more likely to outperform their competitors. With more diversified pool of candidates, the organizations have a greater number of people to make choices between so as to staff the adequate candidate at the adequate position i.e. from each according to his ability, to each according to his needs. Diversity in the organization helps it to tackle all the uncertainties prevailing in the business environment from all sectors be it technology, management or any other wing of the organization and becomes an asset for the company. 


\section{Shifting Focus}

With the fast-moving world where everything is changing swiftly, it is important for the organizations to equip their employees with just not skilling during their orientations but rather polishing them every now and then. It is believed that approximately one third of the total workforce will be fully transformed by 2030 because of Automation and Artificial Intelligence. Now where things can be done with the ease of a click of a key, the employees must be totally trained to be tech savvy's as it saves both time and resources. According to a LinkedIn survey, companies that provide better training have a 53 percent low er attrition rate, which lowers hiring costs and increases productivity.

Employees must learn new skills and businesses must keep up with the latest technology, whi ch is why training and re-skilling are critical.

Augmented reality, for example, can provide employees with a more realistic experience.

Amazon, Walmart, and $\mathrm{PwC}$ have all announced plans to re-skill significant portions of their workforces in the coming years. The challenge for other companies that follow will be to focus on long-term re-skilling efforts rather than designing one-time training programmes. Re-skilling entails treating the workforce as adaptable rather than viewing each employee as having a fixed role. If you have talented employees but their area of expertise is becoming obsolete, you don't want to simply wait for them to become obsolete and then hire someone new, Instead, re-skill them so that you can put their talent to use elsewhere. The first step is to gain a clear understanding of your organization's talent ecosystem, which includes technologies, agile processes, and systems [or ways of working] that enable greater connectivity. The next step recognizes jobs which include the skills and competencies that over-ride with upcoming jobs. The last step is to create re-skilling pathways and critical experiences that will move your people out of 'stagnant' roles.

Even before the current crisis, changing technologies and new ways of working were disrup ting jobs and the skills required to perform them. The McKinsey Global Institute estimated in 2017 that automation and artificial intelligence would force 375 million workers, or $14 \%$ of $t$ he global workforce, to change occupations or learn new skills by 2030. According to a recen t McKinsey Global Survey, 87 percent of executives are experiencing or anticipate skill gaps in the workforce within the next few years and concluded that to emerge stronger and continue to be in the race organizations need to boost up and re-skill their employees. ${ }^{2}$

\section{Managing Necessity}

Being capable of managing remote employees necessitates a mental leap, especially for more traditional-minded managers. At first, business leaders who are used to measuring productivity based on employees' "desk time" and visible activity levels may find the transition to remote work strange and unwieldy. Employees may also feel disoriented at first as they adjust to significant changes in their daily routines. To effectively lead a remote team, managers may discover that they need to relax their grip a little while still holding employees 
accountable. Employees in a shared office space may find success by focusing on what gets done and whether it meets well-defined quality standards in the absence of the ability to continuously monitor them. It's also beneficial to be open to experimenting with technology and meeting formats. In other words, whether planned months in advance or in response to a natural disaster or a global disorder, successful pivot to virtual work necessitate managers' willingness to rethink how they lead their teams. They must also become acquainted with telecommuting best practices and be prepared for some trial and error.

Consider how Yahoo! CEO Marissa Mayer ended the company's remote-working experiment in 2013, observing that the company needed to return to being "one Yahoo!", or how HP Inc. did the same that year. Specific reasons could have differed. However, in each case, the disadvantages of large-scale remote work outweighed the benefits. These drawbacks stem from the organizational norms that underpin culture and performance-ways of working as well as standards of behaviour and interaction - that aid in the creation of a common culture, the generation of social cohesion, and the development of shared trust. To lose sight of them during a significant shift to virtual-working arrangements risks eroding trust, cohesion, and shared culture in the long run. When this happens, remote workers can quickly feel isolated, disenfranchised, and unhappy, as a result of unintentional behaviour in an organization that failed to build a coherent model of, and capabilities for, virtual and inperson work. The sense of belonging, common purpose, and shared identity that motivates us all to do our best work fades. Organizational performance suffers as a result. But considering the post disorder times it has become essential for the organizations to go hybrid and hence the firms should come out with the best possible technique of dwindling both the in-person employees as well as the virtual employees and leaders. The culture should provide a sense of belongingness, cohesion and build trust in the employees and they should not feel left out in order to generate maximum productivity.

\section{Quicker And Evidence Based Talent Management Techniques}

Since Talent Management is one of the most critical areas for a corporate, it has to be based on some evidences that the technique is reliable. It should be reliable because, if at all the technique goes wrong, the entire organization will have to suffer.

Some real evidence-based Talent Management Techniques which are put into use these days are:

\section{Atmosphere Of Trust:}

Building a Climate of Trust is an evidence-based performance management practice that businesses should prioritize. Whether or not a climate of trust is established will be largely determined by your management team's actions. As a result, the organization must concentrate on managerial behaviours and ensure that they are conducive to trust building. Every time a senior official act in a way that contradicts your organization's culture, trust is broken. Consider how you can call them out or, at the very least, hold a mirror to their actions, perhaps starting with 360 or peer-to-peer feedback. It is nebulous and affected by a great many things but largely the behaviour of managers and leaders. To build trust, the entire organization must be aligned if you are attempting to embed good performance management practice. It is critical to keep this in mind from the start. 


\section{Alignment Of Objectives Or Strategies:}

It is believed that problems with strategic alignment are caused by employees who do not understand the overall business goals from the start. They also don't understand how their role contributes to these objectives. The key here is to ensure that the business planning process begins as early in the year as possible. Managers must persuade the Board that if they want their employees to know what is expected of them, they must establish and communicate performance goals early on. Managers must then explain to their teams how the individual goals they have set for themselves actually align with the overall business goal. They should understand the 'why' of what I'm doing.

\section{Rewarding Excellence and Contribution:}

It is believed that when organizations seek to reward their employees, it does not have to involve money. It could include taking time off, sending employees on a development programme, or serving on an employee panel to help shape the new company culture. People can be rewarded in a variety of ways. It is about being creative and thinking outside the box about what these rewards could be and aligning them with the person in question's interests or motivations. People are motivated by a variety of factors, many of which are not monetary in nature. Understanding what motivates them is critical, as is using a trusted, fair system to determine who should receive a reward for their efforts.

Talent management can be as large as the HR function or as little as a collection of initiatives focused at individual and organisational development. Talent management is used by a variety of companies for a variety of reasons. This is determined by the size of the organisation and its commitment to the practice. It might be as basic as a yearly interview with all staff to discuss their strengths and developmental needs. This could be used to match personnel to the company's future initiatives and for succession planning. There are many more wide-ranging benefits than the ones mentioned above. The advantages are as follows:

- Right Person in the right Job: People decisions are given a strategic objective when their abilities and strengths are properly assessed. The skill or competency mapping allows you to inventory the organization's skill inventories. This is particularly significant from both the organization's and employee's perspectives, because the correct individual is placed in the right position, and employee productivity rises. Job satisfaction is also higher since there is a greater match between an individual's hobbies and his job profile.

- Retaining the top talent: Despite changes in the global economy, attrition continues to be a major source of concern for businesses. Retaining excellent people is critical to market leadership and expansion. Companies that fail to retain their best employees risk losing out to competition. The emphasis now shifts to developing employee retention programmes and tactics in order to recruit, develop, retain, and engage top talent. Employee career development must be addressed, and while succession planning is underway, individuals who are on the radar must be kept informed so that they are aware that their efforts are being recognised.

- Better Hiring: The quality of an organization's personnel determines its overall quality. Having skill at the bottom is the best method to have talent at the top. It's no surprise, then, that talent management programmes and trainings, as well as recruiting assessments, have become an important part of HR operations in recent years. 
- Understanding Employees Better: Employee evaluations provide management with in-depth information on their employees. Their development needs, career goals, strengths and weaknesses, abilities, and likes and dislikes are all factors to consider. As a result, it's much easier to figure out what inspires whom, which is quite beneficial. Process of job enrichment.

- Better professional development decisions: When a company understands who its high-potential employees are, it is easier to invest in their professional development. Because development necessitates investment decisions in the individual's learning, training, and development, whether for growth, succession planning, or performance management, an organisation is unsure where to make this investment, and talent management simply makes it easy for them.

Apart from that, having a good talent management culture influences how companies rank themselves as places to work. Furthermore, if employees are pleased with the organization's talent management processes, they are more inclined to believe in the organization's future. As a result, employees are more motivated and engaged, determined to surpass their competitors and ensure their company's market leadership position. If the disorder has taught us anything, it's that we're more adaptable than we realized. Employers are finding ways to be more flexible, and employees are learning to be more efficient, from adjusting schedules to accommodate helping children with online schools to transitioning to remote work almost overnight. In fact, 94 percent of employers reported that productivity remained the same or increased after implementing remote work, and 83 percent said they intend to continue to provide flexible leave policies.

Many organizations may be unable to make compensation changes during an economic downturn. Instead, look for other innovative ways to address employee dissatisfaction.

- Recognize and reward top performers.

- Create low-cost or no-cost employee wellness programmes.

- $\quad$ Concentrate on ways to increase employee autonomy and flexibility.

- Develop a culture of cross-training and professional development.

- Begin an employee holiday or celebration to commemorate the achievement of key performance indicators.

In addition to optional measures, there are some state and federal policies in place that may have an impact on your workforce, such as the Families First Corona virus Response Act. Some restrictions and requirements differ by state or locality, so make sure you are familiar with the rules in all areas where you have employees.

\section{Replacing With Flat Organizational Structure}

People are, without a question, an organization's most valuable resource. Recruiting the best employees in the industry has become a major concern for businesses today. In such a competitive environment, talent management has emerged as a critical method for identifying and filling a company's skill gap by recruiting high-value personnel from the sector. It's a never-ending cycle that begins with people being targeted. The procedure governs the entry and leave of talented individuals from a company. The importance of talent management in business cannot be overstated. The stages of talent management are- 
- Understanding the Requirement: This is the preliminary stage, and it is critical to the overall success of the process. The basic goal is to figure out how much talent is needed. The primary tasks of this stage are to create job descriptions and specifications.

- Sourcing the Talent: This is the second step of the talent management process, in which the greatest talent in the business is sought. The major activity is to find persons who meet the requirements.

- Attracting the Talent: Because the entire process revolves around this, it is critical to attract competent people to work with you. After all, the primary goal of the talent management process is to hire the top professionals in the field.

- $\quad$ Recruiting the Talent: From here, the actual hiring process begins. This is the point at which people are invited to become members of the organisation.

- Selecting the Talent: Meeting with different people with the same or different qualifications and skill sets as stated in the job description is part of this process. Those that pass this phase are invited to join the company.

- Training and Development: Following the hiring of the best individuals, they are trained and developed to produce the desired results.

- Retention: It is, without a doubt, the main aim of the talent management process. Hiring them does not totally fulfil the aim. Pay package, work specification, challenges involved in a job, classification, personal growth of an employee, recognition, culture, and the fit between job and talent are all elements that influence employee retention.

- Promotion: No one can have the same job title or responsibilities in the same organisation. The importance of job enrichment cannot be overstated.

- Competency Mapping: The next phase is to evaluate employees' abilities, development, ability, and competency. Focus on behaviour, neuro - heterodox - attitude, knowledge, and future opportunities for development if necessary. It gives you a quick indication of whether or not the person is suitable for further advancement.

- Performance Appraisal: It is vital to assess an employee's real performance in order to determine his or her true potential. It's to see if the person can handle additional tasks or not.

- Career Planning: If an employee is capable of handling job pressure and more duties, management should organise his or her career such that he or she feels rewarded. It's important to acknowledge their work in order to keep them for a longer amount of time.

- Succession Planning: Succession planning is concerned with who will succeed whom in the near future. The person who has given his or her all for the organisation and has been with it for a long time deserves to be at the top. Management must choose when and how succession will occur.

- Exit: When a person retires or leaves the organisation, the process comes to an end.

The talent management process is extremely complicated, making it tough to manage. The entire procedure is designed to put the right person in the right location at the right time. The major challenge is finding a good match between the work and the individual. Today, the majorities of new employees wants to be their own bosses and are dissatisfied with rigid organizational norms and multiple levels of reporting. When the organization is flat, new employees and even long-term employees feel like they have a certain status and that their values and opinions are respected, and this is when their productivity is at its peak. 
Management theorists have always regarded self-organization as a desirable mode of operation because we all know the drawbacks of bureaucratic approaches," says Dr Julian Birkinshaw, professor of strategy and entrepreneurship at London Business School. Under Robertson's decentralized model i.e. the concept of flat organizations, all employees are given the freedom and responsibility to complete their work without reporting to a boss. Management responsibilities are divided into roles and distributed among employees. A series of self-organizing 'circles' are formed for jobs that require more collaboration. It's much more efficient, and only need a few meetings because each role description clarifies what is expected. It has also noticed a significant decrease in staff turnover since implementing the new approach i.e., it is fantastic for employee retention. Further,:

- It raises employees' levels of responsibility within the organisation.

- It eliminates unnecessary layers of management and improves employee coordination and communication speed.

- Employees find it easier to make decisions when there are fewer levels of management.

Majority of new age businesses comes up with idea of flatter organizations. According to Kunal Bahl, co-

founder of ecommerce retailer Snapdeal.com, which has only two layers between the call cen tre agent and the top boss: "One of the most important factors determining our success is spee d. We decided to have minimal layers in order to be agile, truly attached to the ground, and tu ned in to our customers." Marico, despite being a traditional FMCG company, is a flat organi sation with fewer decisionmaking layers."A flat organisational structure has always been a pa $\mathrm{rt}$ of our culture. We believe it promotes faster decisionmaking and allows us to support our $\mathrm{v}$ alue of action bias ", says Milind Sarwate, Marico's group CFO and chief HR officer.

\section{Glance}

Infosys Consulting TTM approach focuses on unifying your talent ownership silos from the CHRO (employed talent), the CPO (extended talent), and the CIO (digital talent [bots]) to create a new centralized, aggregate view of talent. This is no easy task and will necessitate significant organizational changes, but the payoff will be incredible. Using a five-pronged strategy, Infosys unique TTM 2020 framework envisions a total transformation across the spectrum of the employee lifecycle. The five-pronged strategy that Infosys is currently adopting for its talent management is:

1. Total Talent Diagnostic

2. Total Talent Design

3. Total Talent Implementation

4. Total Talent Digitization

5. Total Talent Operations

\section{APPLE}

Apple is a multinational corporation that has become one of the most valuable companies in the world due to its innovative management strategies. Because of its superior leadership, the technology industry continues to outperform its competitors. The staff's availability of great 
talents, as well as its one-of-a-kind approach to talent management Its Talent Management approaches has enabled the company to increase workforce productivity and innovation, resulting in high performance. The company employs a Lean Talent Management Approach, which aids in productivity. Apple prioritizes workforce productivity per employee by calculating revenue per worker or profit per employee. The company's philosophy is "having less is more," which means that the leadership is concerned with having fewer employees who are more productive and innovative. Employee recruitment prioritizes hardworking, committed, and detail-oriented candidates over diversity and other factors. It does not provide any training or development programmes for its employees, but requires them to do so in order for them to develop skills on their own. Every year, several complaints are filed, but the company promises to make changes and improve employee relations. The mission of the company is to provide the best to consumers by providing innovative hardware and software while focusing on issues such as market expansion and marketing techniques.

\section{Conclusion}

Talent management is constantly changing as a result of workforce changes, economic pressures, and technological advancements. More than just paying employees well is required for effective and efficient talent management. It is about taking their needs into account and treating them with dignity, respect, and fairness. It is not only the right thing to do, but it also helps to retain employees, improve employee engagement, and can even have an impact on sales and customer service. Fostering a respectful culture allows employees and businesses to succeed through hard work and creativity. The human resources industry, and particularly talent management, is undergoing rapid transformation. Everything is in flux, from the expansion of AI functionality to the challenges of talent and the skills gap. It is not easy to implement effective talent management practices.

At the same time, the industry is brimming with opportunity. There has been an impressive amount of innovation that has enabled businesses to solve specific problems such as hiring bias and a lack of workplace diversity. Companies that embrace these changes and constantly reinvent their talent management strategies will be better positioned for long-term success. And that process begins with selecting the appropriate software. Talent management may be difficult in the coming year, but that doesn't mean software selection should be. Talent management has been highlighted as one of the most important HR concerns for meeting future business objectives. Any corporate organization's existence and long-term development are dependent on it. Neglecting talent management is suicide for a firm, especially in today's high-stakes commercial environment.

One of the most difficult issues that firms face in today's talent-hungry economy is attracting, assessing, training, and retaining exceptional personnel. The end-to-end process of planning, recruiting, developing, managing, and rewarding people throughout a company is known as talent management. Human resources are the single resource that distinguishes one organisation from another. It gives a company a competitive edge while also assisting in the development of long-term growth. Companies all throughout the world are likewise dealing with a talent shortage. Many jobs lack qualified people with the necessary skill sets. The greatest problem for today's HR managers is attracting the appropriate personnel and keeping them in the company. As a result, talent management is a difficult and time-consuming 
responsibility for managers. Employee engagement and employer branding may be utilised as a strategic strategy for retaining and managing personnel. Talent has triumphed in the "War of Talents." As a result, today's businesses view talent management as a strategic weapon in the war for talent.

Disorder - 19 disorder has left an indelible mark on human behaviour, thinking, and decision-making. Sustained periods of adversity are known to affect people's psyche and behaviour, sometimes permanently. This has ramifications for managership and the workplace. A detailed investigation of the pain spots, such as those indicated in the findings section above, is required. Before making any impresarioial choice, there are several behavioural and attitudinal changes that must be addressed and considered. Some individuals experience a newfound awareness of surfaces, space, and other people. According to a poll, three out of ten individuals increasingly strive to avoid direct contact with public objects like elevator buttons and doorknobs. As a result, de-densification solutions must also address appropriate circulation tactics in addition to desk space. If circulation decreases congestion in one direction, it should also contain lots of nearby, clearly indicated "stepping-aside" places where people may pass with enough room.

For many years, the danger of flu and colds has been there in the workplace, but the potential severity of DISORDER-19 exposure has raised public and personal safety awareness to new heights. Workers can anticipate to return to the workplace with heightened awareness of their personal safety, if not outright fear. Personal hygiene has been a more frequent and important issue in recent years. The current crisis has affected mental health in a variety of ways, from anticipatory grief to some, to compounding effects on those already suffering from depression. Along with economic and routine work stress, employee wellbeing has never been so ardently been in the need of attention. Offices would find it difficult to strike the right balance between communal and private spaces.

Flexible working environment is going to be a new normal and deemed as a necessity rather than a privilege. In the future, flexibility will no longer be an extra amenity or bonus - it will be a necessity. There shall be such new trends and changes, given that disorder is here to stay and there are subsequent waves of disorder, or at least threat of it. This has potential of leading to a lot of disruptions in operations and logistics of the businesses, time to time, which adds to the uncertainty. Thus, impresarios have to adjust to the new normal, adapt to the uncertainty, and find innovative ways to navigate through them. How exactly will this adaptability be worked out is there to find out?

\section{References}

- $\quad$ https://www.mckinsey.com/business-functions/risk-and-resilience/ourinsights/disorder-19-implications-for-business

- $\quad h t t p s: / / w w w . n a t u r e . c o m / a r t i c l e s / s 41562-020-0884-z$

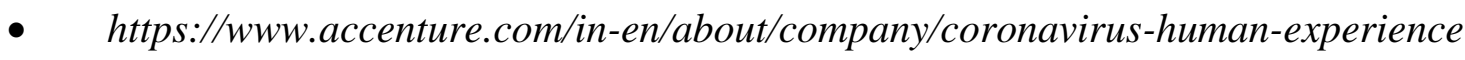

- $\quad h t t p s: / / w w w . a c c e n t u r e . c o m / i n-e n / a b o u t / c o m p a n y / c o r o n a v i r u s-b u s i n e s s-e c o n o m i c-$ impact 
- Inés Ruiz-Rosa, Desiderio Gutiérrez-Taño, Francisco J. García-Rodríguez; Social Impresarioial Intention and the Impact of DISORDER-19 Disorder: A Structural Model, Departamento de Economía, Spain

- Yuan ZhiSeah; DISORDER-19 and Its Effects on Creative neuro - heterodox attitude towardOpportunity-Motivated Managership: Before and after Lockdown, School of Humanities and Behavioural Sciences, Singapore University of Social Sciences

- Nelson, R.R.; Dosi, G.; Helfat, C.E.; Pyka, A.; Saviotti, P.P.; Lee, K.; Winter, S.G.; Dopfer, K.; Malerba, F. Modern Evolutionary Economics: An Overview; Cambridge University Press: Cambridge, UK, 2018.

- $\quad$ https://www.workdesign.com/2020/06/five-post-disorder-behaviours-and-creative neuro - heterodox attitude-that-will-reshape-the-workplacel 